\title{
A white-hot liquid earth and geological time
}

\author{
Professor James Geikie D.O.L., LL.D., F.R.S.
}

To cite this article: Professor James Geikie D.O.L., LL.D., F.R.S. (1900) A white\#hot liquid earth and geological time, Scottish Geographical Magazine, 16:2, 60-67, DOI: $\underline{10.1080 / 00369220008733126}$

To link to this article: http://dx.doi.org/10.1080/00369220008733126

曲 Published online: 27 Feb 2008.

Submit your article to this journal

山 Article views: 4

Q View related articles $\sqsubset$ 


\section{A WHITE-HOT LIQUID EARTH AND GEOLOGICAL TIME.}

\section{By Professor James Geikie, D.C.L., LL.D., F.R.S.}

IT is sometimes brought as a reproach against geology that we cannot obtain from it any definite statement as to the time which has elapsed since the oldest sedimentary strata began to be deposited. Unfortunately the evidence that appeals most strongly to a student of the stony science is not often of a kind which others can readily appreciate. He may occasionally attempt a rough computation of the time required to form a given thickness of strata, but the conditions that determine the rate of erosion and deposition are so varied that he las but little faith himself in the exactness of the results obtained. Were twenty geologists invited to make just so many independent estimates of the duration of the - Carboniferous period, possibly no two of those estimates would agree even approximately. But each geologist would doubtless subscribe readily to the statement that the period in question probably extended over several million years. It is needless to tell a knight of the hammer that estimates so vague as this must be quite unreliable and unworthy of credence. A traveller who has painfully made his way across some trackless continental area, without maps or any means of measuring exactly the distance traversed, if he cannot tell us precisely how many miles he has walked, will nevertheless feel assured in his own mind that the journey has been a very long one. The reality of a great distance covered is just as patent to him as if his route had been carefully mapped and accurately measured. Just so is it with the geologist. Judging from what is known of the operations of nature in our own day-reasoning, in short, from the present to the past-he is convinced that the history of our earth from the introduction of life cannot be comprised within a few million years. Deeply impressed by the prolonged succession of geological events - the multitudinous changes of land and sea-the protracted process of earth-sculpture-the great oscillations of climatethe gradual coming in and dying out of whole faunas and floras-it is not strange that he should sometimes speak of the time during which life has existed on the earth as "incomprehensibly vast." It is not at all likely, indeed, that geology will ever be able to tell us how many years have passed away since life first appeared upon our planet. Her answer to all inquiries of this kind will doubtless continue to be that of the old man in the ballad :-

\footnotetext{
"I cannot tell, I do not know,

But 'twas a long, long time ago."
}

But if the geologist has no unqualified faith in estimates of past time even when these are based upon the average rate at which natural operations proceed at present, he nevertheless recognises that calculations of this kind lend a certain precision to lis appreciation of the work done in the past. They can never be more than approximations to the truth, but even so they have convinced him that the geological past is not "practically infinite," as was at one time supposed; he knows now that 
the great demands formerly made by his science, upon the bank of time are not justified by our knowledge of the present. . But while such computations as he is able to make have set bounds to his horizon, they have , at the same time assured him that geological time cannot be comprised within the narrow limits recently prescribed by Lord Kelvin.

When the attention of physicists was first turned to the question of geological time great things were loped for. Assuming the riebular hypothesis to be true, and supposing, therefore, that the earth had cooled down from a red-hot liquid condition, it was conceivable that physical research should be able to give us an approximate date for the beginning of geological time-for the period when encrustation was completed and the earth became fitted to be the abode of life. Some five-and-thirty years ago, therefore, geologists were interested to learn frum Sir William Thomson (now Lord Kelvin) that the time which has elapsed since the surface of the earth was everywhere red hot could not be less than 20 millions nor more than 400 millions of years. By and by, however, this generous range of time was reduced, and geologists then heard that all their wonderful earth-history must be comprised within 100 million years or less. Even this moderate allowance is now cut down, and Lord Kelvin tells them he has good reason for judging that the time which has passed since the consolidation of the earth was between 20 and 40 millions of years, and probably mucl nearer 20 than 40 .

There must be few, if any, geologists willing to admit that " 20 or 25 million years" is a reasonable estimate of the time which has elapsed since the period of encrustation. We have, indeed, reliable grounds for doubting whether even the former estimate of 100 million Jeas can span the whole course of geological history. Many, therefore, have come to view the physical conception of the evolution of the globe with considerable doubt, and to believe that physicists have overstated their case. One cannot fail to see that, after all, the physical theory is not founded upon facts, but assumptions. It is based upon the hypothesis that the whole surface of the earth was at one time enveloped in an ocean of red-hot or white-hot liquid lava. If we accept this assumption then we must apparently also accept Lord Kelvin's conclusions. But those conclusions do not harmonise with the geological evidence, and one is forced, therefore, to suspect either that the assumption on which the whole physical theory rests is not true, or that there is some unsuspected error in the elaborate computations based upon it.

If the physical theory be well founded, it ought surely to throw some light on the origin of our great mountain ranges. These are long wrinkles formed, as geologists believe, by the contraction or shrivelling of the earth's crust. Let us see, then, how the physical theory works out in the case of such mountains.

If the earth be a cooling body which has solidified from a liquid condition, it is obvious that there must be a passage downwards from the cooled crust into the still uncooled nucleus. At some depth from the surface, therefore, a level will be reached at which the interior has not yet begun to cool and contract. All the matter above that level constitutes the crust, which we may for the moment think of as consisting of 
two concentric shells. The inner one, resting immediately upon the uncooled nucleus, is cooling and therefore contracting, and consequently must be in a state of tension. But owing to the enormous pressure of the overlying crustal shell, it cannot yield to tension by actually rupturing. It is simply stretched, and the stretching must diminish upwards until a level is attained where it will cease altogether. That level we may consider the boundary of the two crustal shells. Above this boundary the crust is not subject to lateral tension, but to lateral compression; the external crustal shell is not stretching but shrivelling, and that process increases upwards so as to reach its maximum at the surface. There are thus two kinds of contraction to which the earth's crust is subjected, namely, circumferential below, and radial above. Where the former is in excess stretching is most marked, where the latter prevails lateral compression is dominant-where the one equals the other there is no strain. It is, therefore, only in the outer crustal shell above this neutral zone or level-of-no-strain, that folding of the crust can take place.

On the assumption that the earth has solidified from a white-hot liquid condition, it follows that the thickness of the upper crustal shell must be proportional to the time which has elapsed since encrustation was completed. To put it in another way, the neutral zone or level-ofno-strain must formerly have been much nearer the surface than now, and must continue to descend with the gradual cooling of the glube. On the supposition that encrustation took place 100 million years ago, some physicists have estimated the depth of the neutral zone to be two miles or so, while others put it at seven or eight miles. But if only $2 \bar{j}$ million years have passed since the earth at the surface was a white-hot liquid, it is obvious that the neutral zone cannot be nearly seven miles from the surface, for "the depth is proportional to the time since consolidation." How far, then, does this conclusion harmonise with the results of geological investigation?

All the larger mountain chains of our globe belong to the class of Folded Mountains, and owe their origin to deformation of the crust. So far as known, mountains of this class are composed of a very great thickness of strata, exceeding in some cases 50,000 feet. Originally arranged in approximately horizontal positions, the beds have subsequently been subjected to intense lateral compression, whereby they have been flexed, folded, convoluted, contorted, and dislocated in a most extraordinary manner. So severe, indeed, has been the compression that in some cases the strata have lost a fourth and sometimes even a half of their former extension. In the Jura Mountains between the Lake of Geneva and St. Claude, for example, the contraction by folding is equal to three miles, or one-fourth, while in the Eastern Jura it is greater. But not only are the strata closely folded and convoluted, they frequently show approximately horizontal lines or planes of displacement along which masses of rock, measuring many hundred feet in thickness, have been pushed forward for distances of ten miles and more. In a word, all the phenomena characteristic of mountain-structure demonstrate that this is the result of intense lateral compression. 
Many have been the views held as to the origin of folded mountains; it is now generally believed, however, that they are due to crustal wrinkling, consequent on the secular cooling of the globe. Other possible sources of lateral compression have been suggested, but each of these has proved entirely insufficient. The contraction-theory alone seems to give a satisfactory explanation of mountain structure and its concomitants; failing it, indeed, the origin of folded mountains becomes inexplicable. Assuming, then, that rock-folding on the large scale is the result of shrinkage and consequent wrinkling, let us take a few wellknown geological facts into consideration. The Appalachian Chain came into existence towards the close of the Palæozoic era. Now the strata entering into the formation of these mountains attain a thickness of 40,000 feet. The width of the strata before lateral compression affected them was over 300 miles, but is now less than 250 miles. In other words, the strata, by folding and lateral displacement, have lost probably more than 50 miles of their original width. If we accept the physical conception of crustal evolution, we must therefore believe that the external crustal shell attained a thickness of more than seven miles before the close of Palæozoic times. But according to the physicists it would take 100 million years of cooling to cause the level-of-no-strain to descend to a depth of seven miles from the surface. Take another case : in the European Alps-an uplift of relatively recent age-we find a thickness of over 50,000 feet of strata. On the same principle, therefore, we must infer that the neutral zone had descended ten miles before the close of Tertiary times; and this would imply very considerably more than 100 million years of cooling. Now, if physicists have not erred in their methods of estimating the depth of the level-ofno-strain, it would seem evident that encrustation must have taken place more than 100 million ycars ago, and assuredly very much more. than 25 million years ago.

There are certain other considerations which increase one's doubts as to the adequacy of I Lord Kelvin's theory of crustal development. Even if we admit the possibility that within 25 million years from the period of encrustation the level-of-no-strain had descended so far as to allow of the folding and plication of an external crustal shell ten miles in thickness, it seems more than doubtful whether the radial contraction of the globe would suffice to produce the phenomena of mountainstructure. The Rev. O. Fisher lias made several interesting calculations to show that folded mountains cannot owe their origin to contraction of the earth's crust- that is to say, a crust which has solidified from a molten mass. Assuming the temperature to be $7000^{\circ} \mathrm{F}$. at the time of solidification, and that 98 millions of years have elapsed since the period of encrustation, Mr. Fisher estimates the total radial contraction of the globe at six miles. With a lower initial temperature and a shorter period of cooling the contraction would necessarily be less. Thus, taking $4000^{\circ} \mathrm{F}$. as the temperature of consolidation, and 33 million years as the time that has elapsed since encrustation, the total radial contraction, according to the same physicist, would be only two miles. But if, with Lord Kelvin, we assume the temperature to have 
been about $1420^{\circ}$ C. $\left(2588^{\circ}\right.$ F.) and the time of cooling 20 to 25 million years, the radial contraction would not be even so much as two miles. Now a radial contraction of two miles would give a circumferential or lateral contraction of fourteen miles or thereabout. It is obvious that so limited an amount of contraction is entirely inadequate to explain the phenomena of mountain-structure. The strata buckled up in individual mountain-ranges have, in a word, experienced a greater amount of contraction than the physical theory of crustal evolution would allow for the whole globe. Mr. Fisher and other physicists have, therefore, maintained that folded mountains cannot owe their origin to wrinkling of the crust consequent on the secular shrinkage of the globe. But their estimates and conclusions only tend to show that the theory of crustal evolution at present in vogue is probably not well-founded. Here, then, we come to an impasse-geologists are convinced that the convolutions, great horizontal displacements, and other phenomena of our folded mountains can only be the result of contraction; while physicists present them with a theory which cannot be harmonised with that conclusion.

The larger inequalities of the earth's surface-the continental plateaus and oceanic basins - are not more readily accounted for by the physical theory. On the supposition that a white-hot lava ocean formerly enveloped the globe, it seems reasonable to infer that cooling would take place equally everywhere, and that encrustation, therefore, would result in the production of an approximately uniform surface. The radial contraction of a globe so encrusted could not possibly give rise to the larger surface-features just referred to. Lord Kelvin admits that "if the shoaling of the lava-ocean up to the surface had taken place everywhere at the same time, the whole surface of the consistent solid - would be the dead level of the liquid lava all round, just before its depth became zero. On this supposition," he continues, "there seems no possibility that our present-day continents could have risen to their present heights, and that the surface of the solid in its other parts could have sunk down to their present ocean depths, during the twenty or twenty-five million years which may have passed since the consistention status (i.e. the state of complete solidification) began, or during any time however long." He would therefore account for the continents and oceanic basins by supposing that these inequalities of surface "are due to heterogeneousness in different parts of the liquid which constituted the earth before its solidification." It is very hard, however, to understand how such a lava-ocean should have varied so much in its chemical composition. Presumably its component materials must have been as well-mixed as are those of igneous rocks in the original molten magma from which they solidify. Lord Kelvin himself in picturing the conditions that took place during the shoaling of his hypothetical lavaocean, describes how the loss of heat from the white-hot surface would produce very rapid cooling of the liquid within a few centimetres of the surface, and in consequence great downward rushes of this cooled liquid, and-upwards of hot liquid, spreading out horizontally in all directions, when it reached the surface. If such were the conditions, surely the 
white-hot liquid must have been tolerably well stirred, and it is difficult to conceive how its chemical composition should have varied to such an extent as to give rise on cooling and solidification to well-defined continental plateaus and oceanic depressions. If, following Professor Chamberlin, we "conceive the hypothetical lava-ocean to have been. one great solution, stirred by convectional and other currents, and depositing crystals as supersaturation arose from change of temperature or from change in the solution itself, there seems not much more reason to suppose that its deposits would have been localised persistently on the sites of the present continents than to suppose that the present enveloping solution-the ocean-if duly concentrated, would localise in a similar way the crystals which it would throw down."

"We come, then, to the general conclusion that if a white-hot lava ocean enveloped the globe 20 or 25 million years ago our folded mountains cannot owe their origin to the wrinkling and shrivelling of the crust, nor can the larger inequalities of the earth's surface be due to movements either of elevation or of depression. But the evidence of compression -of crustal squeezing, thrusting, and lateral and vertical displacement-is so conspicuous and so incapable of being misread that geologists are not likely to give up their contraction theory. They will insist that physicists who speculate on the subject of crustal evolution must first take into consideration the actual facts of crustal deformation and the genesis of rocks. No theory, however brilliant and plausible, can meet with acceptance if it be inconsistent with the well-ascertained results of geological and petrological observation.

In a very interesting essay recently published in Science (June and July 1899), Professor Chamberlin has examined Lord Kelvin's theory in some detail. He points out that this theory is confessedly based upon a hypothesis. To use Lord Kelvin's own words, it is "founded on the very sure assumption that the material of our present solid earth all round its surface was at one time a white-hot liquid." The certitude of this assumption is challenged by Professor Chamberlin, who remarks, by way of preface to his criticism, "that the postulate of a white-hot liquil earth does not rest on any conclusive geological evidence, however generally it may be entertained as a probable hypothesis." It is, in point of fact, chiefly a deduction from the high internal temperature of the earth, and from the nebular lyppothesis. But, as Professor Chamberlin says, "it remains to be shown that the high internal temperature may not also be the sequence of an earth which grew up by meteoric accretion with sufficient slowness to remain essentially solid at all stages"-the highlyheated state of the interior necessarily resulting from the self-compression of the mass during its accretion.

We may believe with Lord Kelvin that the earth was almost certainly built up of meteorites falling together, but are not necessarily compelled to infer that the result of their impact would be a gaseous or even a white-hot liquid condition. Everything would depend on the rate at 'which the bodies clashed together. If they fell in simultaneously at a sufficiently high velocity, no doubt an intensely hot condition would follow-either liquid or gaseous. But if they fell sporadically, at as 
great intervals as they do to-day, a low surface-temperature would be the result. If, on the other hand, the ingathering took place at some intermediate rate, an intermediate thermal state would follow. Professor Chamberlin therefore concludes that "before a white-hot condition can be regarded as a safe assumption, it must be shown that the meteoroids would necessarily fall together at a highly rapid rate, otherwise the heat of individual impacts would be lost concurrently, as is now the case, and would not lead to general high temperature." Probably the meteorites constituted a swarm or belt revolving round the sun in the path now followed by the earth, and resembled in their distribution those shoals of minute bodies which form the rings of Saturn. So long as these minute bodies are under the tidal influence of that planet they cannot clash together to form an independent satellite, but we do not know how they would behave were they to be removed so far from Saturn as to be beyond the sphere of specially intense tidal strain. Escaped from the tidal infuence which had kept them apart, would they at once clash together? Professor Chamberlin thinks that it is difficult to demonstrate "even the method by which the meteorites would aggregate, much less the rate, or even to demonstrate that, apart from extraneous causes, they would fall together at all. Is not the presumption in such a case," he continues, "favourable to a slow rather than to a rapid aggregation?" The probable behaviour of a swarm of meteorites revolving round the sun in the orbit of the earth is in truth a very hard problem to solve. For, as Mr. Chamberlin remarks, it "involves the balance between gravitative forces, revolutionary forces, and tidal forces, and the gravitative forces are not simply those between the meteorites mutually, but those between the meteorites, and the central solar body, and the exterior planetary bodies." "Is it certain," he asks, "that these forces would be so related to each other as to produce a swift ingathering of the whole swarm or belt, or, on the other hand, an ingathering prolonged through a considerable period? If the latter be the case (and, in the absence of demonstration, is it unreasonable to think it quite as probable as the opposite), are there any imperative grounds for assuming that a liquid state of the earth would result?"

After indicating that, so far as regards the amount of sensible heat at the beginning of the habitable stage of the earth's history, there is no great difference between Lord Kelvin's hypothesis and his own, Mr. Chamberlin remarks that in a meteor-built earth, solid from the beginning, much less heat would be lost by convection than in the case of a liquid earth. But the two hypothetical earths would differ most notably in regard to the proportion of potential energy convertible into heat which remained within the earth when full grown. In a white-hot liquid earth the material would be readily arranged according to its specific gravity, so that its potential energy, or energy of position, would be practically exhausted. But this would not be the case in a solid earth built up by the accretion of meteorites. In such a case there could be no free readjustment of material, so that heavier and lighter stuff would be confusedly commingled throughout the whole body of the earth, "except only so far as the partial liquefaction, and the very slow, plastic, 
viscous, and diffusive rearrangement of the material permitted an incipient adjustment to gravitative demands." Readjustment would thus proceed very slowly, potential energy becoming gradually converted into heat as local liquefaction and internal movements permitted the sinking of the heavier and the rise of the lighter material-a process which is presumably still in progress. This descent of the metallic and other heavy materials towards the centre, and reciprocal ascent of lighter materials from the central region towards the surface, is supposed to have its superficial manifestation in volcanic action. So that " besides developing heat in proportion to the work done, it incidentally brings the hotter material of the interior toward the surface, and thus increases the sub-superficial temperature." It is a kind of slow convection, not radically different from that which is supposed to bave taken place in the hypothetical liquid earth. In the case of the latter, however, the heat was brought to the surface and dissipated before the earth could have been habitable, while in the case of an earth solid from the beginning the process would be delayed, and the heat become available even while the surface was fitted to be the abode of life.

In a liquid earth the conditions would necessarily favour a ready adjustment of materials, such chemical and mineral combinations taking place as best accorded with the internal pressures. But in a heterogeneous solid earth all combinations of the kind would be restrained and delayed, and could take place only slowly during the gradual readjustment of the internal material. Thus throughout the ages a process of rearrangement and recrystallisation would be carried on under high pressure, and the density of the interior would increase, while heat would, at the same time, be set free. Increasing density "would furthermore permit the shrinkage of the whole mass and the consequent intensification of its self-gravitation, and this would in turn result in further development of heat."

Such is a brief outline of some of the leading features of Professor Chamberlin's alternative hypothesis of a meteor-built earth, solid from the first. Whether it will stand the test of radical criticism remains to be seen. But it certainly satisfies geological requirements, which are not met by Lord Kelvin's hypothesis. In particular, as Professor Chamberlin points out, the loss of heat from the earth, as computed by physicists, and the shrinkage resulting therefrom, are quite incompetent to produce the observed inequalities. The phenomena of our folded mountains, as we have seen, imply a degree of deformation which the liquid-earth hypothesis forbids. We must agree with Professor Chamberlin, therefore, that the formation of folded mountains, and the still larger inequalities of the earth's surface, demand a more deep-seated agency than that which is supplied by superficial loss of heat; and we are at one with him in thinking "that an earth of heterogeneous constitution, progressively reorganising itself, would give larger possibilities of internal shrinkage, and that the shrinkage must be deep-sented as well as superficial." 